\title{
Research on the Development and Problems of Guandong Province Carbon Emmission Market Construction
}

\author{
Chen Jian, Liu Chenglin, Lin Jingchuan \\ International Business Faculty, Beijing Normal University (Zhuhai), Zhuhai, P. R. China
}

Email address:

chenjian $a$ bnuz.edu.cn (Chen Jian), cjstacey $@ 126 . c o m$ (Liu Chenglin)

\section{To cite this article:}

Chen Jian, Liu Chenglin, Lin Jingchuan. Research on the Development and Problems of Guandong Province Carbon Emmission Market Construction. Science Discovery. Vol. 7, No. 4, 2019, pp. 194-199. doi: 10.11648/j.sd.20190704.12

Received: April 18, 2019; Accepted: July 4, 2019; Published: July 19, 2019

\begin{abstract}
The climate anomalies around the world are still outstanding. Under the UN's United Nations Framework Convention on Climate Change (the Framework Convention) and the Kyoto Treaty, governments have adopted a country-specific reduction in $\mathrm{CO}_{2}$ initiatives such as greenhouse gas emissions etc.. After experiencing the pilot implementation of the carbon trading rights market in seven provinces and municipalities, in December 2017, the "Chinese National Carbon Emissions Trading Market Construction Plan (Power Generation Industry)" officially launched the national carbon emissions trading system. This paper outlines the empirical measures and development status of the domestic carbon emission trading rights market, lists the development status of the Guangzhou Carbon Emissions Exchange in Guangdong Province, and the shortcomings on carbon accounting, carbon emission data reporting, carbon allowances, etc. It also gives suggestions on the upper layer design, the establishment of sound carbon market infrastructure, capacity building and carbon financial instrument innovation, with a view to the long-term development of low-carbon economy in Guangdong Province that will provide further valuable experience for the construction of the national carbon market.
\end{abstract}

Keywords: Sustainable Development, Carbon Emission Trading System, Carbon Finance, Guangdong Province, Problem Research

\section{广东省碳排放市场的发展现状及问题研究}

陈健, 刘呈琳, 林静钏

北京师范大学珠海分校国际商学部工商管理系, 珠海, 中国

邮箱

chenjian@bnuz,edu.cn(陈健), cjstacey@126.com(刘呈琳)

摘要：世界各地气候异常问题依旧突出, 联合国制定的《联合国气候变化框架公约》 (United Nations Framework Convention on Climate Change，简称《框架公约》）和《京都条约》下各国政府采取了因国置宜的减少 $\mathrm{CO}_{2}$ 等温室气体 排放的举措。中国在经历了7个省市地区的碳交易权市场的试点施行后, 2017年12月，《全国碳排放权交易市场建设方 案(发电行业)》正式启动全国碳排放交易体系。本文概述了国内外碳排放交易权市场的经验举措及发展现状，列举了 广东省的广州碳排放权交易所发展现状, 以及在碳核算、碳排放数据报告、碳配额等问题上的短板，并在上层设计、 碳市场基础设施建立健全、能力培养和碳金融工具创新四个方面给出建议, 以期广东省低碳经济的长远发展, 为全国 碳市场的建设贡献宝贵的经验。

关键词：可持续发展, 碳排放权交易市场, 碳金融, 广东省, 问题研究 


\section{1. 绪论}

碳排放权交易市场是一个近年来兴起的将碳资产作 为商品买卖的交易市场, 碳排放权作为一项有价值的商品 可以在市场上流通买卖, 由此形成的碳市场为碳排放权交 易体系市场。碳排放权要获得合理“价格”，前提是总量固 定保证稀缺性和配额分配切断垄断性保证价格公平, 以欧 盟碳排放交易体系（EU ETS）的总量交易（cap-trade）为 例,根据国家总体减排标准，国家设定一个碳排放总量。 同时, 为了不使较多的配额导致碳价格低迷而使碳成本无 法对企业造成实质性的影响或者过少的碳配额导致企业 减排成本压力的提升，并且考虑不同地区，不同行业，不 同企业的碳排量不同, 国家通过有偿和无偿配额的方式分 配给不同地区碳排放额度, 并运用市场上的供求规律与竞 争机制来制定碳价格, 超额完成减排目标的企业可以将多 余的配额进行储蓄, 出售或者托管, 没有完成指定排放额 的企业需要到市场上购买配额或者通过国家核证自愿减 排量 (CCER) 机制抵消。

广东省的低碳经济发展面临着不小的压力, 许多电力, 钢铁, 造纸等行业仍然能源消耗高, 但是生产效益低, 以 较低的劳动成本和环境成本为代价发展粗放型经济。本文 主要列数了一些广东省碳市场仍存在的问题, 比如在碳市 场交易的活跃程度上，碳金融创新工具的广泛应用上，在 碳配额发放的比例和定价上等仍存在问题。广东省需要参 考国际国内的有效经验，尤其是发展时间久，经验充足的 EU ETS。需要进一步根据国际及国家政策完善出台相应 的地方性法律法规; 更深层次探索完善碳交易排放权交易 体系的相关系统的建立健全; 创新性发展碳金融工具, 使 制造业与金融业紧密联系, 增强碳交易市场流动性, 减少 融资成本和交易成本，降低投资风险，为金融机构、公司 以及个人的低碳发展提供稳定的发展环境。扩大辐射带动 作用, 让广东省争做低碳经济绿色金融的开拓者先行人。

\section{2. 文献综述}

目前关于碳交易体系的理论主要有碳市场形成的理 论基础, 碳市场的核心组成部分、形成机理以及国内外的 发展现状、问题和经验。调节治理气候问题在政府宏观调 控的基础上，也需要企业和个人的共同努力。

冯登艳（2018）中指出,新古典经济学理论引入税收 政策，即碳税，是政府宏观财政政策的一部分，企业通过 平衡减排成本和税收成本之间来管理碳排放，也成为现有 的配额制度的原理之一[1]。Emiisons Trading Worldwide Status Report 2018中也提及, 日前南美洲国家如智力、哥 伦比亚正在实施碳税, 并考虑实施碳排放交易体系[2]。它 的缺点为没有把排放权市场化, 因此科斯定理明确把排污 作为一种权利在市场上买卖, 成为了碳排放权交易市场的 理论基础[1]。王文举 (2018) 提到, 碳市场的核心有三个 方面, 分别是碳排放指标的核算, 以碳核算为基础发放的 碳配额, 以及反映供（碳配额）求（控排量）关系的碳价 格[3]。碳排放的监测与计算是碳排放监测报告与核查体系 (MRV) 体系的基础, 张丽欣等（2013）指出国际上欧
盟以企业内部排放设施为单元进行排量的计算, 出台了不 同行的企业生产设备的质量技术指标等 [4]。Agencies

(2015) 指出, 加利福尼亚州的MRV体系对排放设施的 监测要求精确度更高, 并对微量排放进行估算[5]。曾雪兰 等（2016）指出，广东省MRV体系的监测报告层级分为 企业整体排放单元，排放工序单元以及排放设备单元，但 没有强制规定所有企业进行重点排放设备的核算报备, 因 此精准度有待提升[6]。在碳配额发放方面, 陈毅非等(2018) 指出, 目前国内碳排放权交易市场处于初级阶段, 碳排放 配额发放以无偿为主, 有偿为辅, 但广东省率先垂范, 引 入竞拍方式有偿发放配额, 并将竞拍所得与碳金融工具结 合起来，形成对低碳项目投融资的碳基金[7]。国际方面， Emiisons Trading Worldwide Status Report 2018显示: 区域 性强制减排组织区域温室气体倡议（RGGI）实现配额的 全部有偿分配, 能够准确的反映出需求量, 通过无形的手 来实现排放权的公平定价[2]。李布（2010）指出由于欧盟 成员国国体、经济发展程度等因素的不同, EU ETS采用 分权式的治理方法, 成员国根据国情确定本国排放总量以 及国内各个控排企业排放权的比例分配, 最后成员国统一 汇总成为欧盟排放总量配额 [8]。此碳交易体系区域性的特 点可以为各试点地区在我国碳市场的建立背景下如何发 展提供参考性意见。但EU ETS的发展并非一帆风顺, Zoltán nagy等(2016)指出, 目前其处于发展的第三阶段 （2013-2020年），但为防止再次出现金融资产价格暴跌 的情况, 欧盟将在2019年1月内引入市场稳定储备 (MRS), 使市场上竞拍后超出的配额量永久取消以解决市场失衡 的问题 [9]。碳配额的价格决定机制产生在碳交易权的一级 和二级市场上, 邹海英等 (2018) 指出, 在无偿分配过多 的情况下, 一级市场存在过多配额供应, 导致二级市场反 映碳排放权价格的失灵。在免费配额发放少于控排企业需 求时, 一级市场配额成交完成, 也盘活了二级市场, 并且 形成的价格成为拍卖有偿配额的基础[10]。王巍等(2018) 指出我国碳排放权交易价格受工业产值, 非清洁能源价格, 以及政府定价时参考的国际碳价格的影响, 并且控制能源 价格尤其是煤的价格可以有效控制碳市场的价格 [11]。最 后, 我国要在各试点的基础上建立全国碳排放权交易体系, 仍存在一系列问题, 各试点地区联合制定碳市场法规政策 的自发性不足, 而杨锦琦（2016）指出美国碳市场区域性 明显，但在形成“自下而上”的局面，各地区合作共同制定 交易法案[12]。碳交易市场中除了对碳配额的买卖, 碳交 易所联合商业银行也推出了诸多碳金融产品。吴琦等

（2017）指出, 国际上EU ETS允许英国的BarclayBank为 平台的构建提供专业技术, 而中国的商业银行却无此良机; 美国银行、德意志银行等开展了碳交易价格风险管理等服 务。但中国商业银行存在实际合作碳交易的范围窄、第三 方评级机构的联系不紧密等问题[13]。吴涵（2018）也指 出, 商业银行工作人员碳金融了解程度低, 碳金融研究人 才储备不足 [14]。推广全国性的交易体系必须获得群众的 广泛指出, 但张锦莉（2016）指出, 目前广东省碳惠普制 度的普及性不广，民众使用低碳产品的自发性不足 [15]。 


\section{3．国内外碳金融市场产生发展}

\section{1. 全球碳金融发展}

\subsection{1. 政策背景}

在1992年制订的《框架公约》和1997年通过的《京都 条约》的框架下, 继2005年1月初始运行的EU-ETS之后, 多国政府为了减排承诺的实现, 建立完善了以碳资产为标 的物的新型市场, 催生出多种强制性和自愿性减排体系, 衍生出碳期货等金融工具。两年前出台的《巴黎协定》, 为2020年后全球各级各政府治理环境气候问题节能减排 方案提供方向指导, 发达地区带头减排以及与发展中地区 进行更密切的国际合作。

\subsection{2. 发展现状}

截至2018年, 覆盖全球多达 36 个国家、21个ETS在世 界各地运行发展, 覆盖了北南美洲、欧洲、亚洲、大洋洲 等五大洲[16]。

\section{（i）美洲市场}

2018年1月RGGI重新连接安大略省的cap-trade体系, 并且实现配额 100\%非免费发放。美国加州也将改革此系 统并且运行到2030年, 两个碳交易体系计划从2021年到 2030 年十年内实现碳排放总量降低 $30 \%$ 和 $40 \%$ 。加州对清 洁发展机制 (CDM) 国内国际抵消比例降低四个百分点, 并将保持到 $6 \%$ 至2025年。墨西哥、新斯科舍省、华盛顿 州都在计划或者考虑实施碳排放交易体系[16]。

（ii）欧洲市场

EU-ETS目前正处于其四个发展时段的第三个成长时 段，2030年碳排放总量将比十五年前降低43\%。在2019年 至2023年间，市场稳定储备（MSR）可以从市场上撤回 $24 \%$ 的配额, 以实现配额的重新稀缺和供求平衡, 以促进额外 的减排。2020年后国际抵消额度将不再适用其履约机制[16]。

（iii）澳洲市场

新西兰碳排放交易体系（NZ ETS）是全球包含了最 多行业的体系，开创性的将林业纳入其系统。新西兰政府 将在2020年之前引入配额拍卖机制, 并允许在一定限度内 使用国际抵消比例[16]。

\section{2. 我国碳交易市场的发展}

\subsection{1. 政策背景}

2011年发改委印发了《关于开展碳排放权交易试点工作 的通知》。党的十九大报告指出, 加快推进生态文明体制改 革, 在总结试点地区经验教训的基础上启动全国碳排放交易 体系, 扎实推动全国碳排放权交易市场的建立健全[17]。2017 年12月, 印发《全国碳排放权交易市场建设方案(发电行业)》, 因电力行业排放量大影响广且统计数据完整, 国家以此为全 国试点行业，全国碳排放交易体系自此正式启动。

\subsection{2. 试点地区碳交易市场}

(i) 发展现状

目前国内加上四川自愿性的碳排放权交易所一共有 九家碳交易所。碳交易额和碳交易量最多的均为湖北省, 分别为 74 亿元和 3.3 亿吨。它与上海环境能源所共同为全
国性的碳交易所的系统建设起先导带领作用。广东争取做 大做多碳交易市场仍需要向两地学习借鉴。

（ii）交易主体

交易类会员和服务类会员是买卖主体的两大组成部 分，交易类会员一般包括机构、自然人、托管、公益等会 员, 湖北碳排放权交易中心的经济类会员要求注册资本不 少于 300 万人民币 $[18]$, 上海交易类会员不少于 100 万人民 币[19], 综合类会员净资产多于1亿人民币。而广州的交易 所会员可开展自营, 经济, 托管, 公益等一项或多项业务, 灵活性强, 便于多方向操作[20]。

（iii）交易产品

九大交易所均以CCER和碳排放配额的现货交易为主, 上海清算所和上海交易所也联合推出上海碳配额远期 [21]。 2017年4月27日，中国第一个新型控排企业碳资产管理工 具——配额现货远期交易和远期产品交易CCER在湖北实 现[22]。福建省还推出林业碳汇减排量和碳现货中远期交 易。远期交易的实现有利于降低现货市场货源不到位的风 险性, 保障碳资产的重新整合配置, 或者成为企业套期保 值的金融工具。

CCER用于减扣超出规定额度的碳排放, 天津, 深圳, 广东, 湖北均规定利用CCER进行抵消碳排放抵消比例少 于初始配额的 $10 \%$, 重庆规定不得超过 $8 \%$ 。上海, 北京控 排单位可以利用CCER进行抵消碳排放比例少于 $5 \%[23]$ 。

由于京津冀地区环境问题最为严峻并且牵涉范围广, 北京的国家核证减排项目优先使用于京津冀的大气污染 治理等。北京规定利用北京以外的CCER项目进行抵消少 于 $2.5 \%$, 促使企业提高减排水平。

（iv）金融创新

深圳碳排放权交易所推出国内首个碳金融结构性存 款即绿色结构性存款, 湖北推出全国第一个碳排放权质押 贷款[24]。自此之后, 各个试点地区均推出各类创新性碳 金融产品, 如碳债券, 碳资产托管, 碳基金, 碳排放配额 回购, 借碳交易等。

\subsection{3. 全国碳排放权交易体系}

《全国碳排放权交易市场建设方案(发电行业)》提出 国家将取各试验田经验教训之精华和共性, 在2017年底启 动全国碳市场, 由国家发改委等相关部门统一领导, 并逐 步将各试点地区纳入全国碳交易发展的运行轨道上。并且 现有阶段省市碳交易试点地区继续实施，上海市和湖北省 引领建设注册登记和交易系统[17]。

\section{4. 广东省碳交易市场发展现状及问题}

\section{1. 碳排放权交易试点及金融创新}

(i) 顶层设计

广东省积极响应国家号召, 出台了一系列政策支持广 州市低碳经济发展的相关文件, 包括《广州市关于大力发 展低碳经济的指导意见》、《广州市“十二五”节能规划》、

《广州市国民经济和社会发展第十三个五年规划纲要 （2016-2020年）》也指出要培育壮大碳交易和碳金融市 场。但目前出台的文件以指导文件居多, 对关于低碳经济 
的广东省人大立法性质的法律制度少, 对义务的不履行的 实际惩罚力度小, 因此需要在顶层设计上加强重视。

（ii）交易市场

2012年成为试点的广州碳排放权交易所是第一个考 虑由政府拍卖定价使配额有偿分配的试点, 并且与二级市 场配合定价机制。截至2019年1月广州碳交所一级、二级 市场累计成交量达 0.9 亿吨, 累计成交额达 7.8 亿元。市场 反应良好, 电力等多个行业实现控排目标, 从2014年到 2018年连续四年全部完成配额清缴履约工作。

2015年至2019年, 广东省在云南、贵州进行沼气利用, 江西省发展林业碳汇项目, 在新疆省等西部地区开展光伏 发电等多个CDM项目, 实现多达420万吨的CCER。但从 2016年截止到2019年7月, CCER明显出现出售需求多于购 买需求的局面, 这会导致配额价格的下跌, 而且CDM项 目多坐标于非广东省的地区, 因此会打击广东省内企业的 内部减排的积极性, 不利于企业减排技术的发展和广东省 的环境改善。

\section{（iii）金融创新}

目前有碳排放配额押置贷款，碳排放权远期交易，配 额委托管理，碳资产担保透支，配额回购等一系列碳金融 产品和服务。碳普惠置试点工作在社区、绿色旅游、建筑 及交通领域展开，根据相应的减碳量核算标准，推出可以 实现兑换商业优惠、公共服务的载体一一碳币，以期实现 大众层面的流通性，企业也可将碳币用于碳排放的抵消上。 但是在土木工程、交通出行等领域并没有碳配额的无偿发 放工作，不能与广碳所的碳交易体系的有效对接，会导致 实际参与人数不多, 参与积极性不高, 碳币的流通性弱以 及范围窄等一系列问题。

\section{2. 广东省MRV体制体系}

MRV体系的完善与否, 关系着碳配额制度、碳交易 系统的长远发展, 广东省现有MRV体系运行良好, 2014
年出台了《广东省企业碳排放信息报告与核查实施细则 (试行)》, 但也存在诸多问题, 比如碳排放的监测数据 不完整不准确, 企业对像炉渣、粉尘、飞粉的碳氧化率等 测量精准度低并且成本高。不同的行业由不同的承担单位 制定行业报告指南, 但有些大型企业例如钢铁厂生产活动 兼备钢铁冶炼和自备发电厂两项或多项碳排放设备, 因此 不同的行业指南报告出现的定义, 框架的不同会对企业的 监测和报告带来混乱。核查方面, 广东省不仅在核查前教 育培训地方市发改委, 考核评价核查机构, 在核查后设置 专家数据检查体系, 现场抽复查等双重保险核查程序。[6] 但广东省第三方核查机构的核查费用主要以政府资助为 主, 但北京深圳开始允许企业委托第三方核查机构进行核 查, 核查机构的市场化定价有利于减轻政府成本。

\section{3. 广东省碳排放配额制度}

广东省发改委出台《广东省2018年碳排放配额分配实 施方案》, 其中基本数据如下, CCER和碳普惠核证减排 量(PHCER)可以用来抵消企业的实际碳排放量。标准为, 控排企业2017年度的实际碳排放量的 $10 \%$ 及以下可以用 于帮助企业的减扣配额工作, 广东省外的自愿减排项目不 能超过总CCER抵消比的 $30 \%[25]$ 。

配额的发放以无偿分配为主，政府定价会导致交易市 场不活跃，交易价格不能反映实际碳市价格，从2013年12 月19日到2019年3月18日, 广州碳配额价格从60.17降低到 $21.07,2016$ 年 12 月, 广碳所的交易价格出现历史低值9.00。 CCER项目里, 企业的碳排放数据不是实际排放量, 数据 的核算从项目整体来测量, 而不是来自排放设备, 数据的 不精确会导致配额发放的误差。并且从CCER项目开发到 最终备案需要至少 210 天的时间, 时间久, 程序繁琐, 不 利于配额的及时发放与履约。

表1 2018年度广东省碳排放配额实施方案细节表。

\begin{tabular}{|c|c|c|c|c|c|c|c|}
\hline & 水泥业 & 电力业 & 钢铁业 & 民航业 & 造纸业 & 石化业 & 总计 \\
\hline 控排企业和新建项目企业数量/个 & 65 个 & 78 个 & 55 个 & 5 个 & 65 个 & 20 个 & 288 个 \\
\hline $\begin{array}{l}\text { 纳入标准/万吨 } \mathrm{CO}_{2} \\
\text { 免费配额发放比例 }\end{array}$ & $\begin{array}{l}2 \text { 万吨及以上 } \\
97 \%\end{array}$ & $\begin{array}{l}2 \text { 万吨及以上 } \\
95 \%\end{array}$ & $\begin{array}{l}2 \text { 万吨及以上 } \\
97 \%\end{array}$ & $\begin{array}{l}2 \text { 万吨及以上 } \\
97 \%\end{array}$ & $\begin{array}{l}2 \text { 万吨及以上 } \\
97 \%\end{array}$ & $\begin{array}{l}2 \text { 万吨及以上 } \\
97 \%\end{array}$ & \\
\hline 配额总量 & & & & & & & 4.22亿吨 \\
\hline CCER/PHCER & & & & & & & 150 万吨 \\
\hline
\end{tabular}

\section{5. 广东省碳排放权交易市场可采取的措施}

\section{1. 在上层设计层面}

更好的融入全国碳排放权交易体系并且争做领头羊 成为广东省政府和发改委必须要考量的问题。根据国家制 定的相关方面法律, 行政性法规, 广东省地方政府应出台 人大立法, 增强法律位阶, 并结合地方性规章制度, 进行 职能部门优化调整, 对碳项目审定专家或者工作人员进行 培训, 稳步推进碳交易量交易额的持续增长。在对交易主 体的扩大和审查方面，交易规则的制定、实施、冲突防范 和惩罚方面, 在交易产品的多样性和灵活性方面, 在交易
监管全方位多层次覆盖方面, 在会计税务方面, 都对广碳 所规则的制定提出了更高的要求。更高层面、更宏观、更 高法律效力的法律制定有利于与全国碳市场更稳定的接 轨。

\section{2. 基础设施建立健全层面}

为了更好的推进国家碳排放权交易市场的有序运行, 广东省需要在上海市和湖北省的带领下, 依托现有体系, 配合建设好以下四个系统。

\subsection{1. 碳排放数据监测报送系统 (MRV)}

在监测报告层面, 通用报告指南或者不同行业碳排放 信息报告指南制定的各行业碳排放监测细则需要进一步 
细化和深化, 微量估算指标的出台可以有效提高核算精准 度, 为其他行业提供核算方法。鼓励排放企业的碳资产管 理部门可以通过外包的方式, 引入有资质的评估企业或者 机构等对控排企业自身难以精准测量的排放数据进行监 测。虽成本会出现增高, 但完善的碳排放数据有利于企业 对能源活动的控制, 生产技艺的改进。

在第三方核查层面, 引入市场机制, 发挥市场在独立 审核审计方面的自主性。在与国家碳市场对接的过程中, 广东省政府和控排企业可以通过招标的方式对核查机构 进行选择, 与国内其他碳交易试点地区或者国外试点地区 著名的会计师事务所、咨询服务机构、审核评级机构建立 连接, 在引入无形的手同时与国际上具有碳排放审核程序 经验的企业单位进行密切的合作。

\subsection{2. 碳排放权注册登记系统}

由于广东省是最早进行配额有偿发放的, 控排企业每 年花费一定数额的资金购买碳配额, 在跟全国碳市场对接 的过程中, 允许已购买的按原比例配额进入全国流通, 从 而减少对进行控排企业积极性的打击。广东省在初始碳排 放配额的分配中采取的主要是基于历史数据的分配方法, 对于早期排放量大的企业有偿分配的碳排放权数额多, 而 不利于较早开始低碳减排行为的控排单位或者缺乏历史 数据的新进入企业, 因此在此系统中要对历史数据加以精 准收集, 并且对早期开展碳排放的企业进行鼓励与补偿。 对CCER的碳排数据从减排设备上进行收集, 考虑企业的 生产状况，提高发放碳排额权的灵活性。

实现注册登记和交易系统的有效衔接, 由于CCER从 项目备案到开发的时间久, 程序复杂, 企业可以按照比例 折算出上年度CCER用于抵消本年度的碳额度来进行登记 履约。

\subsection{3. 碳排放权交易系统}

竞拍方式有偿分配不仅与国际配额发放标准相匹配, 而且有利于推动碳配额交易系统上的买卖。水泥, 钢铁等 行业的免费发放额度可以参考电力行业降低到 $95 \%$ 。电力 行业逐步适当减少无偿配额额度。CCER抵消比例也相应 降低, 例如降到 $5 \%$, 规定 $90 \%$ 及以上是在广东省内的自愿 核证减排项目。以增加控排企业的减排成本和压力, 一方 面省内达到更好的减排效果, 另一方面可以控制因排放权 无偿发放过高而导致的配额供多于求，而使碳交易价格持 续低迷，有效增加广碳所的交易量和交易额。

\subsection{4. 碳排放权结算系统}

广碳所应增强与国有四大银行及其他商业银行的合 作, 提高银行交易系统和结算系统的紧密性和联动性, 具 体制定针对碳交易的交易规则, 风险管控措施等, 加强对 广碳所两种会员的资金审核和评定，对现货交易采取日结 的方式，对期货交易采取经济账户保证金的制度有效控制 风险，确保碳资产交易的资金流动性和交易的普及性。

\section{3. 能力培养方面}

广州市发改委联合统计局、能源局等可以共同牵头设 立广州市碳市场建设办公室, 统筹政府, 企业, 机构等各
级碳市场建设工作, 制定发展碳金融的长远战略规划。广 碳所可以与深圳市共同合作, 在股市建立低碳创业板, 允 许中小企业在创业板里融集资金，为CDM项目筹划资金; 并且可以开展多项金融服务, 例如托管, 增信, 交易等; 允许个人爱好者和投资机构对控排企业的股权进行买卖 交易。对控排单位开展能力建设培养, 例如鼓励企业设立 专门低碳管理部门, 做好碳资产管理、减排发展长短期规 划、编制CDM项目预算; 做好碳排放数据收集计算工作, 主动上交数据, 并做好开户、交易、结算等工作; 大力发 展低碳技术或积极主动开展CCER项目, 对接政府办公室 下派的专员, 合作进行碳资产的管理与减排成本进行合理 的核算评估。鼓励企业在内部财务部门或者投融资部门招 聘具有碳金融知识的金融服务人员，或者持有碳交易师和 碳金融师证书的专业人员，专项负责碳资产基金的管理， 碳资产押置贷款, 碳债券的发行与履约, 碳资产现货或远 期交易，风险评估的咨询业务，碳排放配额回购融资等业 务; 鼓励企业积极与高校采取校企合作方式增加碳金融专 业的人才, 聘用高校如华南理工大学的碳金融学人才为其 监测碳排放数据和管理碳资产。有利于降低企业的成本和 为国家培育更多的碳金融人才。个人层面, 广东省发改委 可以和广州科学馆合建“低碳规划馆”, 提高民众的低碳意 识, 推广有碳足迹的手机软件, 或者与民众常用的社交软 件, 如微信, 微博等合作。

\section{4. 碳金融工具创新层面}

增强广东省商业银行对碳金融业务的参与力度、深度 和广度。继续支持并加大商业银行对低耗能, 低排放, 低 污染企业的绿色信贷工作。对碳金融产品进行创新, 深入 挖掘碳金融衍生工具的交易价值, 对碳交易产品开发保险 产品, 对类似CCER质押贷款等金融工具债券化, 以期增 加碳货产品的市场流动性。与第三方评级机构密切合作, 提高对减排项目投融资贷款时资质审核和资产评估的可 靠度[13]。碳惠普制度里, 碳配额的发放和碳交易市场体 系落实到与民众息息相关的行业, 比如日常出行、社区建 设等方面, 依托现有的微信、支付宝等电子支付手段实现 碳币的日常商品化和投资化，提高金融机构、个人投资爱 好者、企业的低碳发展参与度和主动性, 有利于节能减排 计划的全民开展。

\section{6. 结语}

全球气候问题和温室气体控制问题不仅是各国政府, 也是各地企业、人民的共同责任。不同国家根据本国国情 都相应采取了减排措施, 发展中国家虽说目前仍以经济发 展为主, 但节能减排是刻不容缓的。在促进经济发展的同 时, 需要保护好人类赖以生存的环境。

尽管全国碳排放市场已经正式启动并运营, 但碳排放 数据、碳交易平台系统建设、制度体制建设及政策制定等 仍有较远的路要走。本文分析了广东省的碳排放市场现状 及问题, 期待政府和企业未来能够在顶层制度设计、基础 设施建设、专业知识培育和碳金融工具的使用上做到稳定 
有序的发展，成为全球交易制度最完备、交易体系最成熟 的碳货交易市场之一。

\section{参考文献}

[1] 冯登艳, 国内外碳排放市场建设经验及对河南省的启示 $[\mathrm{J}]$. 征信, 2018 。

[2] Emiisons Trading Worldwide Status Report 2018 [R]. Berlin:International Carbon Action Partnership, 2018.

[3] 王文举, 赵艳, 全球市场研究及对中国碳市场的建设的启 示 $[\mathrm{J}]$.东北亚论坛，2019。

[4] 张丽欣, 段志洁, 燕百强, 陈伟, 张礼兴.美国和欧盟温室 气体管理机制对我国电力行业碳排放管理的启示 $[\mathrm{J}]$.中国 电力, 2013 。

[5] Agencies, C. S. California Code Of Regulations [R]. 2015.

[6] 曾雪兰, 黎炜驰, 张武英.中国试点市场MRV体系建设实践 及启示 $[\mathrm{J}]$.环境经济研究, 2016。

[7] 陈毅非, 刘宸毓, 碳排放权交易配额初始分配机制探讨 [J]. 合作经济与科技，2019。

[8] 李布，欧盟碳排放交易体系的特征、绩效与启示 [J].重庆理 工大学学报（社会科学），2010。

[9] Zoltán Nagy, Beáta Gergely ,The Development Of The Emissions Trading Scheme And Of Its Regulation [J]. Curentul Juridic,The Juridic Current, Le Courant Juridique, 2016.

[10] 邹海英, 刘映萍, 广东碳市场价格水平分析及行业影响测 算[J].环境保护与循环经济，2018。

[11] 王嵬, 韩丹丹, 我国碳交易价格影响因素识别及作用机理 分析[J].中国经贸导刊 (中) , 2018。

[12] 杨锦琦,美国碳交易市场发展对完善我国碳交易市场的启 示与借鉴[N].《商情》,2016年。
[13] 吴琦, 温馨, 商业银行发展碳金融业务的机会和建议 [J]. 经济研究参考，2017。

[14] 吴涵, 李伟玲, 林烨, 我国碳金融发展面临的困境及出路以湖北武汉为例 $[\mathrm{J}]$.时代金融，2018。

[15] 张锦莉, 基于碳金融的广州市低碳经济发展研究 [J].合作经 济与科技，2016。

[16] 全球碳市场进展执行摘要2018年度报告[R].柏林: 国际碳行 动伙伴组织, 2018。

[17] 国家发展和改革委员会.全国碳排放权交易市场建设方案 (发电行业) [R].2017。

[18] 湖北碳排放权交易中心.湖北碳排放权交易中心有限公司 经济类会员管理办法（试行）[R].2017。

[19］上海环境能源交易所.上海环境能源交易所碳排放交易会 员管理办法（试行）[R].2018。

[20] 广州碳排放权交易所.广州碳排放权交易中心会员资格和 业务资质申请流程公告[R].2018。

[21] 上海碳配额远期产品推介会成功举行 [EB/OL]. (2016-09-28) [2019-02-24]. http://www.cneeex.com/c/2016-09-28/487931.shtml。

[22] 全国首个碳排放权现货远期交易产品推出[EB/OL]. (2016-04-01) [2019-02-24]. http://www.tanpaifang.com/tanqihuo/2016/0401/51803.html。

[23] 张晴, 试点CCER“存货”大盘点[N/OL]. 21世纪经济报道, 2015-05-16 [2019-02-24]. http://www.sohu.com/a/15237135_115443。

[24] 汪洁, 兴业银行深圳分行推出国内首单绿色结构性存款 [J/OL]. (2014-11-27) [2019-02-24]. http:/www.chinanews.com/fortune/2014/11-27/6822261.shtml 。

[25] 广东发展和改革委员会.广东省2018年度碳排放配额分配 实施方 $[R] 2018$ 。 